\title{
Pengelolaan Panen Kelapa Sawit (Elaeis guineensis Jacq.) di Riau
}

\author{
Harvest Management of Oil Palm (Elaeis guineensis Jacq.) in Riau
}

\section{Nurcahya Destiawan dan Ani Kurniawati"}

${ }^{1}$ Departemen Agronomi dan Hortikultura, Fakultas Pertanian, Institut Pertanian Bogor (Bogor Agricultural University), J1. Meranti, Kampus IPB Darmaga, Bogor 16680, Indonesia Telp. \& Faks.62-251-8629353 e-mail agronipb@indo.net.id

*Penulis korespondensi: ani_kurniawati@yahoo.co.id

Disetujui 4 Mei 2016/ Published online 9 Mei 2016

\begin{abstract}
The internship program was conducted in Sei Air Hitam Plantation, Rokan Hulu, Riau from February-June 2013. Harvest planning is done prior to harvest in order to run with harvesting activities optimally. Harvest planning is performed are the calculation of crop density numbers (AKP), assessed the harvest, labor, transportation, harvesting, crop rotation, harvesting facilities and infrastructures. There are some problems in harvesting procces, such as percentage of harvest that was bellow $<15 \%$, the use of personal protective equipment that were low, crop rotation that were accelerated and harvest quality is not compatible with company standard. Supervision to the harvesting activity should be improved so the quality of harvest compatible with company standard.
\end{abstract}

Keywords: crop density numbers, harvesting oil palm, labor, Sei Air Hitam Plantation

\section{ABSTRAK}

Kegiatan penelitian dilaksanakan di kebun Sei Air Hitam, Kabupaten Rokan Hulu, Riau pada bulan Februari-Juni 2013. Perencanaan panen yang dilakukan adalah perhitungan angka kerapatan panen $(A K P)$, taksasi panen, tenaga kerja, transportasi panen, rotasi panen, sarana dan prasarana panen. Permasalahan yang terdapat dalam kegiatan panen adalah persentase AKP $<15 \%$, pemakaian alat pelindung diri yang rendah, rotasi panen yang dipercepat dan kualitas panen yang tidak sesuai dengan standar perusahaan. Pengasawan terhadap kegiatan panen harus ditingkatkan sehingga kualitas panen sesuai dengan standar perusahaan.

Kata kunci: angka kerapatan panen, Kebun Sei Air Hitam, panen kelapan sawit, tenaga kerja 


\section{PENDAHULUAN}

Kelapa sawit merupakan salah satu komoditas perkebunan yang memegang peran penting bagi perekonomian Indonesia. Produk kelapa sawit dapat digunakan sebagai minyak goreng, bahan kosmetika dan farmasi serta bahan non makanan (sabun, deterjen, tinta cetak) (Mangoensoekarjo dan Semangun, 2003). Kelapa sawit kini semakin poluler karena dapat digunakan sebagai bahan baku alternatif biodiesel.

Kelapa sawit merupakan komoditas ekspor penting sebagai penghasil devisa negara. Menurut BPS (2012) ekspor minyak kelapa sawit (palm oil) mengalami peningkatan baik volume maupun nilainya. Ekspor minyak kelapa sawit meningkat pada tahun 2010 dari 16291.9 ton menjadi 16436.2 ton pada tahun 2011. Nilai ekspor minyak kelapa sawit juga meningkat dari 13 469.0 US\$ menjadi 17261.2 US\$ pada tahun 2011.

Produksi kelapa sawit di Indonesia terus meningkat dengan adanya perluasan areal tanam. Produktivitas kelapa sawit dalam keadaan yang optimal dapat mencapai 20-25 ton/ha/tahun atau sekitar 4-5 ton minyak kelapa sawit (Setyamidjaja, 2006). Produktivitas tanaman kelapa sawit dapat dipengaruhi kegiatankegiatan dilapang seperti persiapan lahan, pemilihan bibit unggul, usaha pemeliharaan dan panen.

Pemanenan merupakan hal yang sangat penting dalam kegiatan produksi tanaman kelapa sawit. Pelaksanaan kegiatan pemanenan kelapa sawit berpengaruh langsung terhadap kualitas minyak yang dihasilkan. Kegiatan dalam pemanenan dimulai dari penentuan kriteria panen, penentuan angka kerapatan panen, taksasi produksi, rotasi panen, penyediaan tenaga kerja yang terampil, teknis panen, pengumpulan hasil dan pengawasan serta pengangkutan panen. Pengelolaan yang kurang optimal terhadap faktor-faktor tersebut akan mempengaruhi hasil panen dan produksi yang dicapai (Lubis, 1992).

Persiapan panen dilakukan sebelum kegiatan panen dilaksanakan. Persiapan ini meliputi perhitungan angka kerapatan panen, taksasi produksi, kebutuhan tenaga kerja dan tenaga pengangkutan, sarana dan prasarana panen, dan rotasi panen. Persiapan panen yang akurat akan memperlancar pelaksanaan panen (PPKS, 2003). Kegiatan penelitian dilatarbelakangi oleh pentingnya sistem pengelolaan pemanenan TBS yang baik tersebut.

Kegiatan penelitian bertujuan mempelajari pengelolaan panen kelapa sawit pada keadaan lapang yang sesungguhnya dengan memperhatikan faktor-faktor yang terkait dengan pengelolaan panen kelapa sawit tersebut.

\section{BAHAN DAN METODE}

Kegiatan penelitian ini dilaksanakan di kebun Sei Air Hitam, Desa Kepenuhan Barat, Kecamatan Kepenuhan, Kabupaten Rokan Hulu, Propinsi Riau. Penelitian dilaksanakan selama empat bulan mulai 10 Februari 2013 sampai dengan 10 Juni 2013.

Metode yang digunakan saat penelitian adalah melakukan pekerjaan secara langsung di lapangan dengan berbagai tingkat jabatan. Bulan pertama penulis bekerja sebagai karyawan harian lepas (KHL). Kegiatan yang dilakukan selama penelitian sebagai KHL adalah pengendalian gulma, pemupukan, leaf sampling unit, penunasan pelepah (prunning) dan panen. Bulan kedua penulis melakukan kegiatan penelitian sebagai pendamping mandor, baik mandor panen, mandor perawatan, mador pupuk maupun kerani afdeling. Kegiatan yang dilakukan selama penelitian sebagai pendaping mandor adalah melakukan perencanaan setiap kegiatan budidaya yang akan dilaksanakan sampai dengan pengawasan pekerja saat di lapang. Bulan ketiga dan keempat penulis melakukan kegiatan penelitian sebagai pendamping asisten. Kegiatan yang dilakukan meliputi penyusunan rencana kerja, mengawasi pelaksanaan kerja, mengarahkan kerja mandor dan mengevaluasi hasil kerja.

Peubah yang diamati pada kegiatan penelitian dengan aspek pengelolaan panen tanaman kelapa sawit di Kebun Sei Air Hitam, First Resources Ltd., Riau adalah sebagai berikut: a) Angka kerapatan panen, b) Tenaga kerja, c) Transportasi panen, d) Sarana dan prasana panen, e) Kualitas panen, dan f) Rotasi panen.

Data sekunder diperoleh dari laporan pengelolaan (bulanan, triwulan, semesteran, tahunan) yang tersedia di kantor kebun. Data sekunder yang mendukung pelaksanaan teknis panen meliputi lokasi kebun, luas areal, kondisi iklim, kondisi lahan, produktivitas, struktur organisasi perusahaan dan rekomendasi pelaksanaan teknis budidaya.

\section{HASIL DAN PEMBAHASAN}

\section{Angka Kerapatan Panen}

Angka kerapatan panen merupakan persentase sebaran pokok yang dapat dipanen pada suatu luasan tertentu. Semakin tinggi persen kerapatan panen maka potensi buah yang akan dipanen semakin besar sebaliknya semakin rendah persen kerapatan panen maka 
buah yang akan dipanen akan semakin sedikit. Perhitungan kerapatan panen bertujuan untuk memperkirakan buah yang dihasilkan, sehingga dapat direncanakan kebutuhan tenaga kerja dan kebutuhan transportsi panen. Dilakukan pengamatan AKP terhadap empat blok panen. Hasil pengamatan AKP dapat dilihat pada Tabel 1.

Nilai AKP pada empat blok panen menunjukan hasil yang rendah. Menurut Tobing dalam Akbar (2008), kisaran nilai AKP 25\% $100 \%$ menunjukkan produksi tinggi, sedangkan nilai AKP 15\% - 20\% menunjukkan produksi sedang. Hasil perhitungan AKP tersebut rendah dapat dikarenakan umur tanama $\mathrm{n}$ yang tua sehinggga produksinya turun. Mayoritas umur tanaman kelapa sawit pada afdeling III berumur 18 tahun. Menurut Lubis (1992), produksi tanaman kelapa sawit akan mengalami penurunan setelah tanaman tersebut berumur 14 tahun.

Perhitungan AKP juga dapat mempengaruhi rotasi panen. Apabila didapatkan hasil perhitungan AKP yang rendah maka akan dilakukan penambahan luas areal panen dari kaveld yang lain agar mendapatkan target produksi. Penambahan areal panen akan menyebabkan rotasi panen bertambah cepat. Pada Afdeling III, dilakukan kebijakan penambahan areal pada saat perhitungan AKP rendah. Kebijakan penambahan areal tersebut dilakukan oleh asisten afdeling.

Tabel 1. Angka kerapatan panen

\begin{tabular}{ccccccc}
\hline Nama blok & Luas blok (ha) & Jumlah pokok & Tahun tanam & $\begin{array}{c}\text { Jumlah pokok } \\
\text { sampel }\end{array}$ & $\begin{array}{c}\text { Jumlah tandan } \\
\text { matang }\end{array}$ & AKP (\%) \\
\hline C34 & 29.64 & 2643 & 1995 & 349 & 25 & 7.16 \\
C33 & 30.03 & 3774 & 1995 & 328 & 26 & 7.92 \\
C21 & 35.35 & 3951 & 2002 & 358 & 54 & 15.08 \\
C26 & 39.4 & 5061 & 1995 & 542 & 44 & 8.11 \\
\hline
\end{tabular}

\section{Tenaga Kerja}

Tenaga kerja panen merupakan hal penting yang harus dipersiapkan dalam perkebunan kelapa sawit. Penyediaan tenaga kerja panen yang tepat akan menunjang kelancaran kegiatan panen dan produksi yang maksimal. Jumlah tenaga kerja panen yang tepat dalam perkebunan kelapa sawit disesuaikan dengan standar yang ditentukan oleh perusahaan.

Tabel 2. Kapasitas pemanen pada Afdeling III

\begin{tabular}{ccccc}
\hline \multirow{2}{*}{ Pemanen } & \multicolumn{2}{c}{ Jumlah TBS yang dipanen } & \multirow{2}{*}{ Rata-rata } \\
\cline { 2 - 4 } & Ulangan 1 & Ulangan 2 Ulangan 3 & \\
\hline 1 & $\ldots \ldots \ldots \ldots \ldots \ldots \ldots \ldots$ & Tandan) $\ldots \ldots \ldots \ldots \ldots \ldots \ldots$ \\
2 & 120 & 100 & 120 & 113 \\
3 & 188 & 145 & 132 & 155 \\
4 & 160 & 153 & 140 & 151 \\
5 & 131 & 151 & 150 & 144 \\
6 & 102 & 122 & 151 & 125 \\
7 & 152 & 190 & 153 & 165 \\
8 & 140 & 151 & 130 & 140 \\
9 & 155 & 180 & 160 & 165 \\
10 & 114 & 150 & 114 & 126 \\
\hline Rata-rata & 148 & 160 & 131 & 146 \\
\hline
\end{tabular}

Sumber: Kantor Afdeling III Kebun SAH (2013)

Pemanen pada afdeling III adalah 44 orang pemanen yang terbagi dalam dua kemandoran. Jumlah tenaga pemanen tersebut kurang jika dibandingkan dengan perhitungan. Hal tersebut dikarenakan dengan asumsi dengan keadaan buah yang tinggi. Berdasarkan pengamatan selama pengamatan penelitian kondisi trek buah terjadi pada bulan Februari sampai Mei. Kondisi tersebut menyebabkan kebutuhan tenaga kerja yang dibutuhkan menjadi lebih kecil daripada perhitungan. Kapasitas pemanen yang tinggi juga menyebabkan perusahaan belum menambah tenaga pemanen. Kapasitas pemanen dapat dilihat pada Tabel 2. Berdasarkan Tabel 2 pemanen sudah melewati basis panen yaitu sekitar 50 tandan (BJR $20 \mathrm{~kg}$ ).

\section{Transportasi Panen}

Transportasi panen bertujuan untuk mengangkut TBS dari TPH ke PKS secepat mungkin. Pengangkutan harus dilakukan secepat mungkin agar tidak terjadi buah restan. Buah restan adalah buah yang sudah terpanen, akan tetapi belum terangkut ke PKS dalam kurun waktu 24 jam. Buah restan akan menurunkan kadar lemak tak jenuh pada saat pengolahan. Kebutuhan alat transportasi perlu direncanakan agar pengangkutan TBS berjalan dengan lancar dan tidak terdapat buah restan.

Kebutuhan alat transportasi dapat ditentukan dengan mengetahui kerapatan panen dan taksasi terlebih dahulu. Kapasitas truk di PT PISP I adalah 5-6 ton/trip. Truk dapat melakukan perjalanan/trip sebanyak 6-7 kali setiap harinya. Afdeling III memiliki dua unit transportasi. Data pengamatan transportasi TBS dapat dilihat pada Tabel 3. 
Berdasarkan pengataman penulis, ratarata waktu yang dibutuhkan untuk memuat TBS satu kali trip adalah 41 menit. Waktu muat dipengaruhi oleh kondisi jalan utama dan jalan koleksi, kebersihan TPH dari gulma dan banyaknya berondolan yang berada pada TPH. Brondolan yang tidak dimasukkan ke dalam karung akan menyebabkan waktu muat semakin lama. Rata-rata waktu yang dibutuhkan truk dari TPH ke PKS adalah 6.5 menit. Jumlah rata-rata tandan yang diangkut oleh truk satu kali trip adalah 264 tandan. Rata-rata tonase yang diangkut satu kali trip adalah $5 \quad 797 \quad \mathrm{~kg}$.

Tabel 3. Pengamatan tansportasi TBS ke pabrik

\begin{tabular}{ccccc}
\hline Unit mobil & Waktu muat (menit) & Waktu ke PKS (menit) & Jumlah TBS (tandan) & Tonase (kg) \\
\hline Mobil A & 45 & 7 & 261 & 5720 \\
Mobil B & 37 & 6 & 266 & 5874 \\
Rata-rata & 41 & 6.5 & 264 & 5797 \\
\hline
\end{tabular}

\section{Sarana dan Prasarana Panen}

Sarana dan prasana panen adalah alat yang digunakan pemanen dalam membantu proses panen. Sarana dan prasana panen perlu digunakan agar proses pemanenan berjalan dengan lancar dan juga untuk menjaga keselamatan pemanen. alat panen yang digunakan adalah egrek, gancu, kampak, angkong dan karung. Alat pelindung diri yang dipakai adalah helm, sepatu boots dan sarung egrek. Data pengamatan penggunaan alat kerja oleh tenaga pemanen dapat dilihat pada Tabel 4.

Seluruh pemanen menggunakan alat panen. Penggunaan alat panen wajib digunakan karena alat-alat tersebut digunakan untuk memanen. Apabila alat panen rusak atau hilang pemanen wajib memberitahu kepada mandor agar dicarikan penggantinya. Data pengamatan pemakaian alat pelindung diri dapat dilihat pada Tabel 4.

Tabel 4. Persentase penggunaan alat kerja dan alat pelindung diri tenaga pemanen

\begin{tabular}{|c|c|c|c|}
\hline \multirow{2}{*}{ Jenis alat } & Mandor A & Mandor B & Rata-rata \\
\hline & \multicolumn{3}{|c|}{ Alat kerja } \\
\hline & \multicolumn{3}{|c|}{ 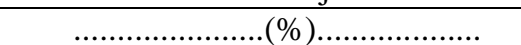 } \\
\hline Egrek & 100 & 100 & 100 \\
\hline Gancu & 100 & 100 & 100 \\
\hline Kampak & 100 & 100 & 100 \\
\hline Karung & 100 & 100 & 100 \\
\hline \multirow[t]{3}{*}{ Angkong } & 100 & 100 & 100 \\
\hline & \multicolumn{3}{|c|}{ Alat pelindung diri } \\
\hline & \multicolumn{3}{|c|}{ 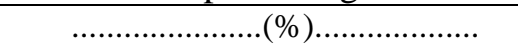 } \\
\hline Helm & 70 & 80 & 75 \\
\hline Sepatu boots & 90 & 90 & 90 \\
\hline Sarung egrek & 100 & 100 & 100 \\
\hline
\end{tabular}

Berdasarkan pengamatan penulis masih terdapat pemanen yang belum memakai helm dan sepatu boots. Hal tersebut dikarenakan kesadaran pemanen tentang pemakaian dan keselamatan masih kurang. Pengawasan dimulai saat apel pagi, apabila ada yang tidak memakai alat pelindung diri akan ditegur dan disuruh untuk segera memakai alat pelindung diri. Pengawasan pemakaian alat pelindung diri dirasakan kurang dikarenakan banyaknya kegiatan selain panen yang diawasi oleh mandor dan asisten. Mandor dan asisten diharapkan memberikan pengarahan tentang pemakaian sarana panen yaitu helm dan sepatu boots.

Sarana dan prasarana lain yang mendukung kegiatan panen adalah jalan, jembatan, titi panen dan TPH. Perbaikan jalan perlu segera dilakukan apabila jalan itu rusak agar pengangkutan TBS berjalan dengan lancar. Perbaikan jalan dilakukan menggunakan dua cara yaitu dengan alat berat dan manual. Penggunaan alat berat dilakukan untuk memperbaiki atau merawat jalan koleksi dan jalan utama. Perbaikan secara manual dilakukan oleh pekerja panen yang tidak mendapatkan tugas panen. Perbaikan jalan secara manual dilakukan pada jalan koleksi yang berlubang dan tergenang air. Perbaikan memilki kelemahan yaitu apabila kerusakan yang berat akan membutuhkan waktu yang lama dan memiliki hasil yang kurang maksimal. Pada TPH dilakukan pengecekan keadaan TPH. TPH yang ditumbuhi gulma dilakukan pengendalian gulma secara kimia maupun manual. Kebersihan TPH akan menentukan seberapa cepat pengambilan brondolan dari TPH.

\section{Kualitas Panen}

Kualitas panen terdiri dari dari mutu buah dan mutu hanca. Pemeriksaan kualitas panen bertujuan untuk menjaga kegiatan berlangsung dengan efisien, mencegah dan memperkecil kerugian dari kegiatan panen, serta mencegah terjadinya kecurangan saat kegiatan panen berlangsung (Panggabean 2009). Pemeriksaan kualitas panen dilakukan oleh mandor panen, krani produksi dan asisten afdeling. Pemeriksaan mutu buah dilakukan di TPH yang sudah terdapat 
TBS panen sedangkan pemeriksaan mutu hanca dilakukan di hanca panen setelah kegiatan panen selesai.

Pemeriksaan mutu buah dilakukan pada 50 TPH dan diulang sebanyak tiga kali. Kriteria buah yang diamati adalah buah matang, kurang matang, mentah, lewat matang, tandan busuk, janjang kosong. Hasil pengamatan mutu panen kemudian dibandingkan dengan standar yang terdapat diperusahaan (Tabel 5).

Hasil pengamatan menunjukkan terdapat mutu buah yang tidak sesuai dengan standar perusahaan. Persentase buah matang, kurang matang, lewat matang dan janjang sesuai dengan standar perusahaan. Persentase buah mentah dan tandan busuk melebihi standar perusahaan yang telah ditetapkan perusahaan yaitu buah mentah $0.23 \%$ dan tandan busuk $0.72 \%$. Persentase buah mentah yang melebihi standar perusahaan dikarenakan ketelitian pemanen dalam menentukan buah matang kurang dan keinginan pemanen untuk mengejar basis dan premi panen. Tandan busuk ada karena pada putaran atau rotasi minggu lalu terdapat buah yang belum terpanen. Setyamidjaja (2006) menyebutkan bahwa panen yang dilakukan melewati waktunya akan mengakibatkan kandungan minyak berubah menjadi ALB yang mengakibatkan mutu minyak kelapa sawit menurun sedangkan panen yang dilakukan sebelum waktunya akan mengakibatkan rendemen yang kurang.

Tabel 5. Hasil pengamatan mutu buah di Afdeling III

\begin{tabular}{cccccccc}
\hline \multirow{2}{*}{ Ulangan } & $\mathrm{n}$ & \multicolumn{6}{c}{ Mutu buah } \\
\cline { 3 - 8 } & $(\mathrm{TPH})$ & Matang & Kurang matang & Mentah & Lewat matang & Tandan busuk & Janjang kosong \\
\hline \multicolumn{2}{c}{} & & $\ldots \ldots \ldots \ldots \ldots \ldots \ldots \ldots \ldots \ldots \ldots \ldots \ldots \ldots \ldots . .(\%) \ldots \ldots \ldots \ldots \ldots \ldots \ldots \ldots \ldots \ldots \ldots \ldots . .$. & \\
1 & 50 & 94.81 & 2.65 & 0.51 & 0.71 & 0.41 & 0.92 \\
2 & 50 & 95.30 & 2.53 & 0.18 & 0.72 & 1.17 & 0.09 \\
3 & 50 & 92.35 & 0.00 & 0.00 & 6.32 & 0.59 & 0.58 \\
\hline \multicolumn{2}{c}{ Rata-rata } & 94.15 & 1.73 & 0.23 & 3.58 & 0.72 & 0.58 \\
\multicolumn{2}{c}{ Standar } & $>89.00$ & $<5.00$ & 0.00 & $<5.00$ & 0.00 & $<1.00$ \\
\hline
\end{tabular}

Keterangan: $\mathrm{n}=$ jumlah TPH contoh setiap ulangan

Pemeriksaan mutu hanca panen dilakukan setelah kegiatan panen selesai. Mutu hanca panen dapat diketahui dengan melakukan pemeriksaan ada atau tidaknya kehilangan hasil pada hanca yang dipanen. Sumber kehilangan hasil di lapangan berasal dari buah yang tidak terpanen, buah tinggal dan brondolan tertinggal. Hasil pemeriksaan mutu hanca dipersentase kemudian dibandingkan dengan standar yang ditetapkan oleh perusahaan (Tabel 6).

Berdasarkan hasil pengamatan menunjukkan bahwa secara umum mutu hanca rata-tata setiap pemanen sudah baik. Persentase rata-rata efisiensi panen yang dihasilkan menunjukkan bahwa tingkat keefektifan dari kegiatan panen mencapai $99.60 \%$ dengan persentase kehilangan hasil sedikit hanya $0.40 \%$

(Tabel 6). Semakin tinggi nilai efisiensi panen maka kehilangan hasil akan semakin kecil. Hasil tersebut perlu dipertahankan oleh perusahaan akan tetapi perlu ditingkatkan evaluasi dan pengawasan terhadap pemanen agar menekan kehilangan hasil hingga 0\%. Evaluasi disampaikan kepada pemanen setiap apel pagi oleh mandor dan asisten.

Tabel 6. Mutu hanca pemanen di Afdeling III

\begin{tabular}{ccccccc}
\hline Ulangan & $\begin{array}{c}\mathrm{n} \\
\text { (orang) }\end{array}$ & $\begin{array}{c}\text { Jumlah buah } \\
\text { terpanen (tandan) }\end{array}$ & $\begin{array}{c}\text { Jumlah brondolan } \\
\text { tinggal (buah) }\end{array}$ & $\begin{array}{c}\text { Jumlah buah } \\
\text { tertinggal (tandan) }\end{array}$ & $\begin{array}{c}\text { Total kehilangan hasil } \\
(\%)\end{array}$ & $\begin{array}{c}\text { Efisiensi } \\
\text { Panen }(\%)\end{array}$ \\
\hline 1 & 6 & 32 & 4.47 & 0 & 0.64 & 99.36 \\
2 & 6 & 15 & 1.31 & 0 & 0.40 & 99.60 \\
3 & 6 & 64 & 2.23 & 0 & 0.16 & 99.84 \\
\hline \multicolumn{2}{c}{ Rata-rata } & & & 0.40 & 99.60 \\
Standar & & & & $>95.00$ \\
\hline
\end{tabular}

Keterangan: $\mathrm{n}=$ jumlah pemanen contoh setiap ulangan

\section{Rotasi Panen}

Rotasi panen adalah waktu yang diperlukan antara panen terakhir sampai panen berikutnya pada tempat yang sama. Rotasi panen yang berlaku di Kebun Sei Air Hitam adalah 6/7.
Menurut Fauzi et al. (2008), sistem 6/7 artinya dalam satu minggu terdapat 6 hari panen dan masing-masing hanca panen diulang (dipanen) pada 7 hari berikutnya.

Berdasarkan data dari kantor afdeling III, terdapat ketidaksesuaian rotasi panen yang 
berlaku. Ketidaksesuaian tersebut berupa rotasi panen yang dipercepat ( $<7$ hari). Data pengamatan rotasi panen dapat dilihat pada Tabel 7.

Rotasi panen dipercepat dikarenakan terdapat hari libur nasional yang mengakibatkan hari panen berkurang. Rotasi panen yang dipercepat juga dapat dikarenakan kerapatan buah yang jarang, sehingga dilakukan penambahan areal untuk dapat mencapai target produksi.

Menurut PPKS (2003), rotasi panen tergantung pada kerapatan panen, kapasitas panen dan keadaan pabrik. Rotasi panen juga dipengaruhi oleh iklim yang menimbulkan adanya panen puncak dan panen kecil. Menurut Sastrosayono (2003), panen kecil terjadi pada bulan April-Agustus sedangkan panen puncak terjadi pada bulan November-Januari.

Panen puncak akan menyebabkan kerapatan panen meningkat, sehingga dibutuhkan waktu yang lama untuk dilakukan pemanenan yang menyebabkan rotasi panen menjadi lebih panjang. Tenaga pemanen harus ditambah pada saat panen puncak agar rotasi tidak menjadi lebih panjang dan buah yang matang dapat terpanen semua.

Pada panen kecil kerapatan panen atau buah yang masak akan menurun. Keadaan buah masak yang menurun akan menyebabkan penurunan produksi. Tenaga pemanen harus dikurangi untuk mengefisienkan pengeluaran. Sastrosayono (2003) menyebutkan keputusan berupa pengurangan tenaga kerja perlu dilakukan agar tidak menimbulkan kerugian. Kerugian yang terjadi dapat berupa pemanen akan memanen buah mentah untuk memenuhi basis panen. Dengan demikian rotasi panen 6/7 dapat dirubah dan disesuaikan dengan keadaan produksi.

Tabel 7. Rotasi panen pada bulan Mei

\begin{tabular}{cclllll}
\hline \multirow{2}{*}{$\begin{array}{c}\text { Nama } \\
\text { blok }\end{array}$} & Tahun & \multicolumn{5}{c}{ Panen ke } \\
\cline { 2 - 6 } tanam & 1995 & $6 / 7$ & $5 / 6$ & $6 / 7$ & $5 / 6$ & $6 / 7$ \\
C34 & 1995 & $6 / 7$ & $6 / 7$ & $4 / 5$ & $6 / 7$ & $6 / 7$ \\
C28 & 2002 & $5 / 6$ & $6 / 7$ & $5 / 6$ & $5 / 6$ & $6 / 7$ \\
C22 & 1995 & $6 / 7$ & $6 / 7$ & $4 / 5$ & $5 / 6$ & $6 / 7$ \\
D24 & & &
\end{tabular}

Sumber: Kantor Afdeling III Kebun SAH (2013)

\section{KESIMPULAN}

Secara umum Kebun Sei Air Hitam telah melakukan manajemen panen dengan baik. Permasalahan yang terjadi dalam pemanenan antara lain persentase AKP $<15 \%$, rotasi panen yang terlalu cepat, persentase mutu buah yang tidak sesuai dengan standar perusahaan dan pemakaian alat pelindung diri belum $100 \%$ yaitu sebesar $75 \%$ untuk pemakaian helm dan $90 \%$ untuk pemakaian sepatu boots. Persentase buah yang tidak sesuai dengan standar perusahaan adalah buah mentah sebesar $0.23 \%$ dan tandan busuk sebesar $0.72 \%$.

\section{DAFTAR PUSTAKA}

Akbar, A. 2008. Manajemen Panen di Perkebunan Kelapa Sawit (Elaeis guineensis Jacq.) Pantai Bunai Estate, PT Sajanag Heulang, Minamas Plantation, Tanah Tumbu, Kalimantan Selatan. Skripsi. Institut Pertanian Bogor, Bogor.

[BPS] Badan Pusat Statistik. 2012. Perkembangan Beberapa Indicator Utama Sosial Ekonomi Indonesia Agustus 2012. Badan PusatStatistik, Jakarta. 54 hal.
Fauzi, Y., Widyastuti, Y, E., Satyawibawa, I., Hartono, R. 2002. Kelapa Sawit:Budidaya, Pemanfaatan Hasil dan Limbah, Analisis Usahadan Pemasaran. Edisi Revisi. Penebar Swadaya, Jakarta. 163 hal.

Lubis, A, U. 1992. Kelapa Sawit (Elaeis guineensis Jacq.) di Indonesia. Pusat Penelitian Perkebunan Marihat, Pematang Siantar. 435 hal.

Mangoensoekarjo, S., Semangun, H. 2003. Pengelolaan Agrobisnis KelapaSawit. Gadjah Mada University Press, Yogyakarta. 540 hal. 